\title{
Role of a "Skeletal Survey" in Primary Hyperparathyroidism: Its Importance and a Format-based Checklist for Clinicians
}

\author{
Amrin Israrahmed ${ }^{1}$, Mayilvaganan Sabaretnam², Sarrah Idrees ${ }^{3}$, Panchangam Ramakanth Bhargav ${ }^{4}$, Amit Agarwal $^{5}$, \\ Raghunandan Prasad ${ }^{6}$
}

\begin{abstract}
Primary hyperparathyroidism (PHPT) is the most common cause of hypercalcemia and its presentation has appeared to have changed from classical disease presentation of bones, stones, moans, and groans to asymptomatic mild mood swings. However, in the developing world, still there are fair proportions of patients who present with classical presentation and they present with advanced target diseases. One such manifestation is a bone disease. Skeletal surgery was employed and is still being employed for surgery of the bone and joints and we discuss the role of the skeletal survey in PHPT.

Keywords: "Parathyroid glands", Hyperparathyroidism, Radiograph, Radiology.

World Journal of Endocrine Surgery (2020): 10.5005/jp-journals-10002-1303
\end{abstract}

\section{INTRODUCTION}

Hyperparathyroidism is a pathological state of elevated serum levels of parathyroid hormone (PTH), which is responsible for increased bone resorption. Biochemically it is seen as elevated serum PTH level or a normal level of PTH with background hypercalcemia. The term "Hyperparathyroidism" was first described by von Recklinghausen in 1891. ${ }^{1}$ It can be classified into three main types: primary, secondary, and tertiary hyperparathyroidism. The commonest cause of primary hyperparathyroidism (PHPT) is parathyroid adenoma, followed by parathyroid hyperplasia ( $10 \%$ cases) and in rare cases, it may be parathyroid carcinoma. ${ }^{2}$ Secondary hyperthyroidism occurs as a response to chronic low calcium levels in renal insufficiency patients, patients with dietary calcium deficiency, and patients with vitamin D deficiencies. ${ }^{3}$ Tertiary causes of hyperparathyroidism include autonomically functioning parathyroid adenoma in patients of chronic kidney diseases.

Parathyroid hormone as we know is the hormone regulating the activity of osteoclast cells, thus elevated PTH levels act on osteoclasts and manifest as metabolic bone diseases. Primary hyperparathyroidism shows few classical features on radiograph which help in clinching the diagnosis.

In the developed countries like the USA and Europe, the incidence of asymptomatic PHPT is high, as the patients are diagnosed early based on routine biochemical screening tests, however, the incidence of patients presenting with symptomatic hyperparathyroidism in developing countries is higher due to neglect and lack of proper screening tests. Hence, we must be aware of the various classical features of radiography in PHTP patients so that early diagnosis and intervention can improve the quality of life for these patients.

Although the findings of primary and secondary HPT show an overlap, we shall be discussing the imaging findings of PHPT in detail. This article aims to describe the various musculoskeletal imaging manifestations (skeletal survey) of PHPT on a format-based approach, so that clinicians are more confident with the diagnosis of PHPT (Table 1).

\footnotetext{
${ }^{1,6}$ Department of Radiodiagnosis, Sanjay Gandhi Postgraduate Institute of Medical Sciences, Lucknow, Uttar Pradesh, India

2,3,5 Department of Endocrine Surgery, Sanjay Gandhi Postgraduate Institute of Medical Sciences, Lucknow, Uttar Pradesh, India

${ }^{4}$ Department of Endocrine Surgery, Vijaywada Hospital, Vijayawada, Andhra Pradesh, India

Corresponding Author: Raghunandan Prasad, Department of Radiodiagnosis, Sanjay Gandhi Postgraduate Institute of Medical Sciences, Lucknow, Uttar Pradesh, India, Phone: +91 8004904501, e-mail: rcoolraghu2001@gmail.com

How to cite this article: Israrahmed A, Sabaretnam M, Idrees S, et al. Role of a "Skeletal Survey" in Primary Hyperparathyroidism: Its Importance and a Format-based Checklist for Clinicians. World J Endoc Surg 2020;12(3):142-147.

Source of support: Nil

Conflict of interest: None
}

A skeletal survey typically includes bilateral anteroposterior (AP) and posteroanterior (PA) projections of hands, forearms, humerus, feet, leg, femur, pelvis, spine, and skull.

\section{Role of Skeletal Survey in Present Era}

Even though skeletal surgery nowadays has a minimal role in asymptomatic PHPT, classical bone involvement, however, has some importance now as well. It can accurately identify the focal and diffuse abnormality of the skeleton and in the young patients with PHPT, it can differentiate development changes and anatomic variations which happen with the growth of the child. CECT scan and $\mathrm{MRI}$ are also useful; however, these $\mathrm{X}$-rays have lower radiation exposure and provide adequate information. It can be used for follow-up of patients once surgery has been performed for PHPT and serial $\mathrm{X}$-rays at appropriate intervals can provide a viewpoint about the improvement that occurs with bone remineralization that occurs after removal of the suspected enlarged parathyroid 
Table 1: A checklist for various skeletal findings from cranial to caudal direction while analyzing a skeletal survey

\begin{tabular}{|c|c|}
\hline$X$-ray & Findings to be reviewed \\
\hline Skull lateral view & $\begin{array}{l}\text { Salt and pepper sign of the skull } \\
\text { (pepper pot skull) }\end{array}$ \\
\hline OPG & - Lamina dura \\
\hline \multirow[t]{2}{*}{$\mathrm{B} / \mathrm{L}$ hands } & $\begin{array}{l}\text { Subperiosteal resorption along } \\
\text { with the radial aspects of the } \\
\text { proximal and middle phalanges of } \\
\text { the } 2 \text { nd and } 3 \text { rd fingers }\end{array}$ \\
\hline & $\begin{array}{l}\text { Terminal tuft erosion } \\
\text { (acroosteolysis) }\end{array}$ \\
\hline $\begin{array}{l}\text { B/L long bones of the } \\
\text { forearm (radius, ulna) }\end{array}$ & $\begin{array}{l}\text { - Subperiosteal resorption along the } \\
\text { medial aspect of the radius }\end{array}$ \\
\hline \multirow[t]{2}{*}{$\mathrm{B} / \mathrm{L}$ humerus } & $\begin{array}{l}\text { - Subperiosteal resorption along the } \\
\text { medial aspect of humerus }\end{array}$ \\
\hline & $\begin{array}{l}\text { Subligamentous resorption at } \\
\text { greater and fewer tuberosities of } \\
\text { the humerus }\end{array}$ \\
\hline \multirow[t]{4}{*}{ CXR PA view } & $\begin{array}{l}\text { - Subchondral resorption at the } \\
\text { lateral end of the clavicles }\end{array}$ \\
\hline & $\begin{array}{l}\text { Subligamentous resorption at the } \\
\text { inferior surface of the clavicle }\end{array}$ \\
\hline & - Superior and inferior rib notching \\
\hline & $\begin{array}{l}\text { Subchondral resorption along } \\
\text { the acromioclavicular and } \\
\text { sternoclavicular joint }\end{array}$ \\
\hline \multirow[t]{4}{*}{ X-ray pelvis } & $\begin{array}{l}\text { - Subchondral resorption at the } \\
\text { symphysis pubis }\end{array}$ \\
\hline & $\begin{array}{l}\text { Subligamentous resorption at the } \\
\text { ischial tuberosity, trochanters of } \\
\text { the femur }\end{array}$ \\
\hline & $\begin{array}{l}\text { Subchondral resorption at } \\
\text { sacroiliac joints more pronounced } \\
\text { at the iliac side }\end{array}$ \\
\hline & $\begin{array}{l}\text { Subligamentous or subtendinous } \\
\text { resorption at anterior inferior iliac } \\
\text { spine }\end{array}$ \\
\hline B/L femur & $\begin{array}{l}\text { - Subperiosteal resorption along the } \\
\text { medial aspect of the femur }\end{array}$ \\
\hline $\begin{array}{l}\text { B/L long bones of leg } \\
\text { (tibia, fibula) }\end{array}$ & $\begin{array}{l}\text { - Subperiosteal resorption along the } \\
\text { medial aspect of the tibia }\end{array}$ \\
\hline \multirow{2}{*}{$\begin{array}{l}\text { Lateral spine (cervical, } \\
\text { dorsal, lumbar) }\end{array}$} & - Rugger jersey spine \\
\hline & - Diffuse osteopenia \\
\hline \multirow{4}{*}{$\begin{array}{l}\text { All joints elbow, knee, hip, } \\
\text { sacroiliac joints }\end{array}$} & - Chondrocalcinosis \\
\hline & - Widening of joint space \\
\hline & - Irregular articular surfaces \\
\hline & $\begin{array}{l}\text { - Indistinct articular margins and } \\
\text { sclerosis }\end{array}$ \\
\hline \multirow[t]{3}{*}{ General findings } & - Osteopenia \\
\hline & - Brown's tumors \\
\hline & $\begin{array}{l}\text { - Intracortical resorption - tunnel- } \\
\text { shaped radiolucency in the cortex }\end{array}$ \\
\hline
\end{tabular}

gland. These $\mathrm{X}$-rays can provide crucial information especially in bedridden patients with severe bone manifestation so that the involved bone can be carefully handled specially during shifting patients for investigations and also positioning of patients in operation theater table for surgery.

We shall first discuss the pathophysiology of various types of osseous findings seen on a radiograph in patients of PHPT:

\section{Salt and Pepper Skull}

Trabecular resorption leads to a smudgy appearance of the trabeculae with poor delineation of the bone marrow in the diploic spaces with the reduced distinction of the inner and outer margins of the skull. These changes reflect on a radiograph of the skull in the form of alternating areas of diffuse and punctate lytic foci, intermixed with areas of sclerosis giving the "salt and pepper" appearance of the skull (Figs 1A and B). Another differential diagnosis of salt pepper skull includes-thalassemia, metastasis, lytic phase of Paget's disease, anemias, and osteoporosis. ${ }^{4}$

\section{Subperiosteal Resorption}

It is described as the destruction of bone beneath the cortical periosteum of long bones. The most characteristic pathognomonic site of subperiosteal resorption is along with the radial aspects of the proximal and middle phalanges of second and third digits and in $95 \%$ of the cases this finding is well appreciated on the hand radiographs ${ }^{5}$ (Fig. 2). It can be seen as lace-like subperiosteal/ intracortical irregularity with thinning of the underlying cortex and sometimes it can appear as a periosteal reaction or pseudoperiostitis. ${ }^{3}$ In later stages, it can manifest as acroosteolysis, which is seen as band-like lucency along the midshaft of the distal phalanx along with tuft destruction, shortening of bone, and associated soft tissue component (Fig. 2C). In isolation, acroosteolysis can also be seen in conditions like scleroderma, thermal injury, traumatic, vascular, or infectious/inflammatory conditions. ${ }^{6}$ Other less common sites of subperiosteal resorption include ribs, lamina dura (bone surrounding tooth socket giving the floating teeth sign, Figs $1 C$ and D), humerus, femur, and upper medial tibia.

\section{Intracortical Resorption}

It is a type of subperiosteal resorption seen along the cortex. It can be appreciated as an oval/cigar or tunnel-like radiolucent area within the cortex of the long bones (Fig. 2).

\section{Subligamentous Resorption}

Subligamentous resorption can be seen at the insertional sites of various tendons and the most common location include ischial tuberosity, trochanters, inferior surface of calcaneus, and clavicle (Figs $3 A$ and $B$ ).

\section{Subchondral Resorption}

This is the result of cartilage destruction seen at articular margins of joints, juxta-articular erosions, followed by healing, fibrous replacement, and new bone formation. The pathogenesis of this finding is PTH-mediated osteoclast activity near the cartilage site. ${ }^{3}$ It manifests on a radiograph in the form of widening of joint space, irregular articular surfaces, indistinct articular margins, and sclerosis ${ }^{6}$ (Figs $3 \mathrm{C}$ and D). The common sites of subchondral resorption include acromioclavicular (clavicular side $>$ acromion), sacroiliac joints (iliac side > sacrum), pubic symphysis, sternoclavicular joints, and interphalangeal joints. Similar changes may be seen at bilateral SI joints and pubic symphysis in cases of inflammatory arthritis and seronegative spondyloarthropathy. ${ }^{5}$ 

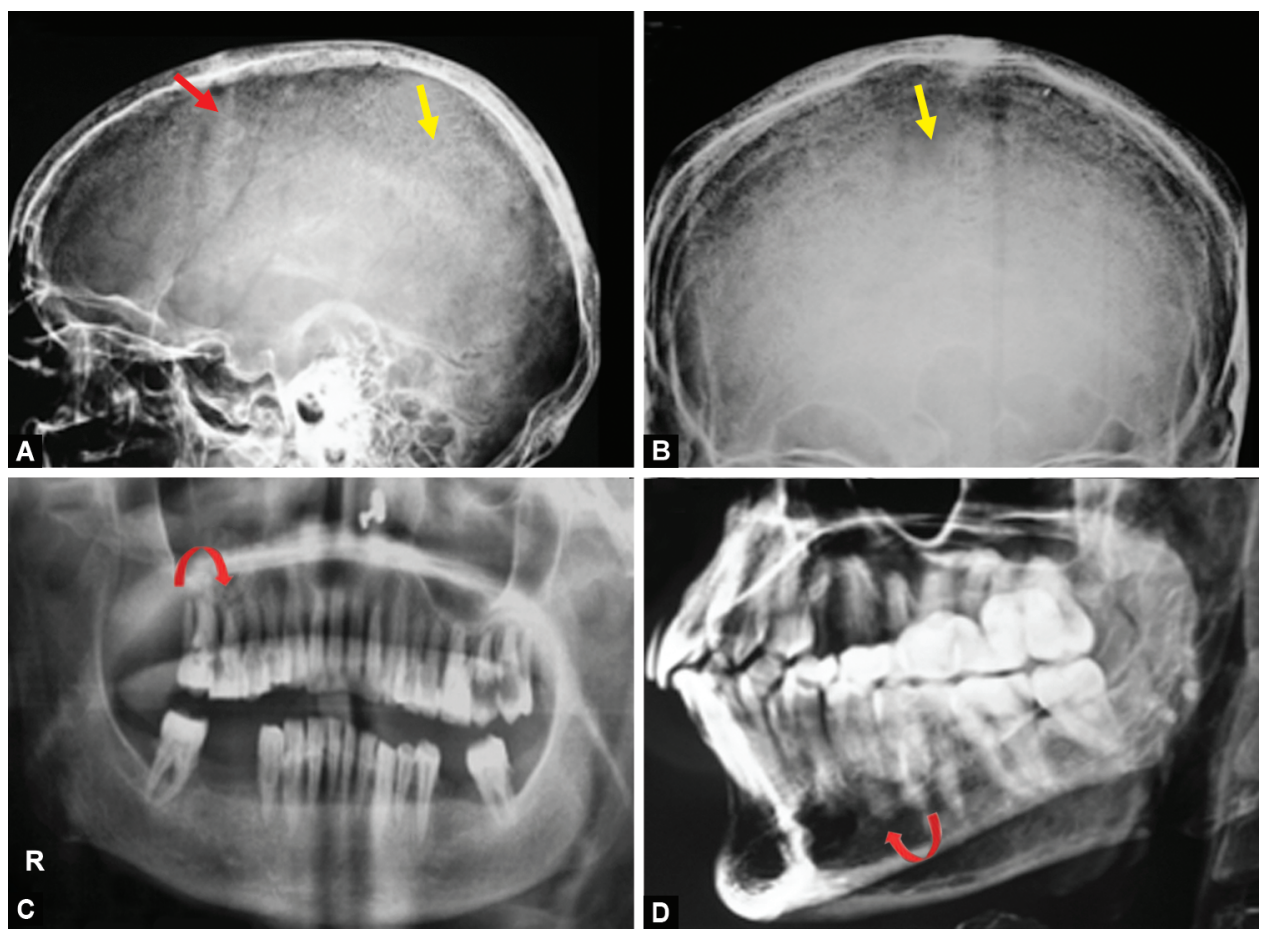

Figs 1 A to D: (A) and (B) are lateral and AP views of the skull showing a "Salt-and-pepper-skull" pattern due to trabecular bone resorption depicted as sclerotic or salt-like radiopaque areas (red arrow in A) mixed with fine areas of lucency like pepper (notched yellow arrow in A and B); (C) and (D) show "Floating teeth" pattern due to subperiosteal resorption of lamina dura around the root of the teeth (curved red arrows in C and D) with diffuse osteopenia of the rest of the mandible bone
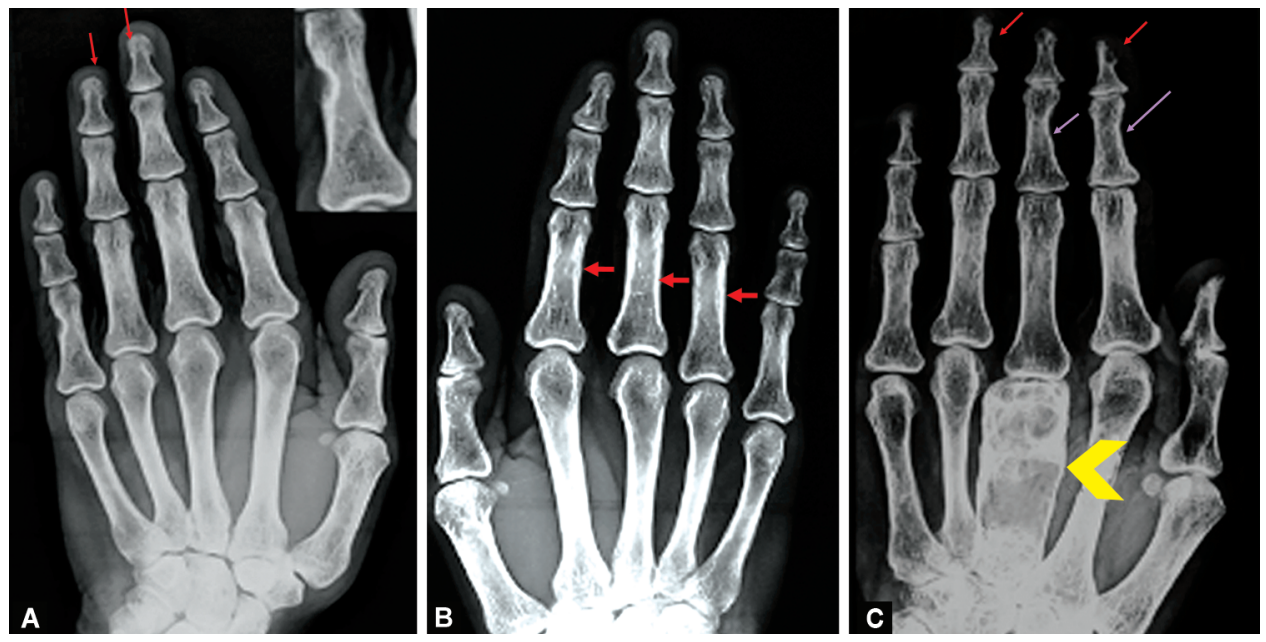

Figs $2 A$ to $C$ : Radiograph of the hand (A to C). (A) Shows areas of intracortical resorption of the proximal phalanx of fifth digit (magnified image in the inset); (B) Shows periosteal reaction or pseudoperiostitis of the proximal phalanx (orange arrows); (C) Shows subperiosteal resorption of the radial aspect of the middle phalanges of the second and third fingers (purple arrows) with advanced tuft erosions of fingertips (red arrow). An expansile lytic lesion in the third metacarpal was brown's tumor (arrowhead in C)

\section{Brown Tumors (Focal Lytic Lesions)}

Nearly $3 \%$ of cases of PHPT are associated with brown tumors. It is described as an area of lucency within the substance of the bone and is also known as osteoclastomas or osteitis fibrosa cystica as they represent areas of marrow replacement secondary to the increased osteoclastic activity. Histologically, they represent giant cell tumors. The marrow is replaced by rich vascularized connective tissue which tends to repeated hemorrhages, leading to hemosiderin deposition, hence the name "brown tumor". ${ }^{7}$ On $\mathrm{X}$-rays, they appear as expansile, soap-bubbly lytic lesions with areas of a cortical thinning, narrow zone of transition without any underlying periosteal reaction and with associated soft tissue component (Figs $4 \mathrm{~A}$ to $\mathrm{C}$ ). Rarely they may be associated with breach of the underlying cortex. ${ }^{8}$

Common locations for these tumors include pelvis, mandible, ribs, long bones, and hands in addition to the vertebrae (more common in the thoracic spine). ${ }^{9}$

CT shows a solid cystic lesion with hemorrhagic components. It gives more specific information on the cortical breach and soft tissue extension around the tumor (Figs 4D to F). MRI is usually 

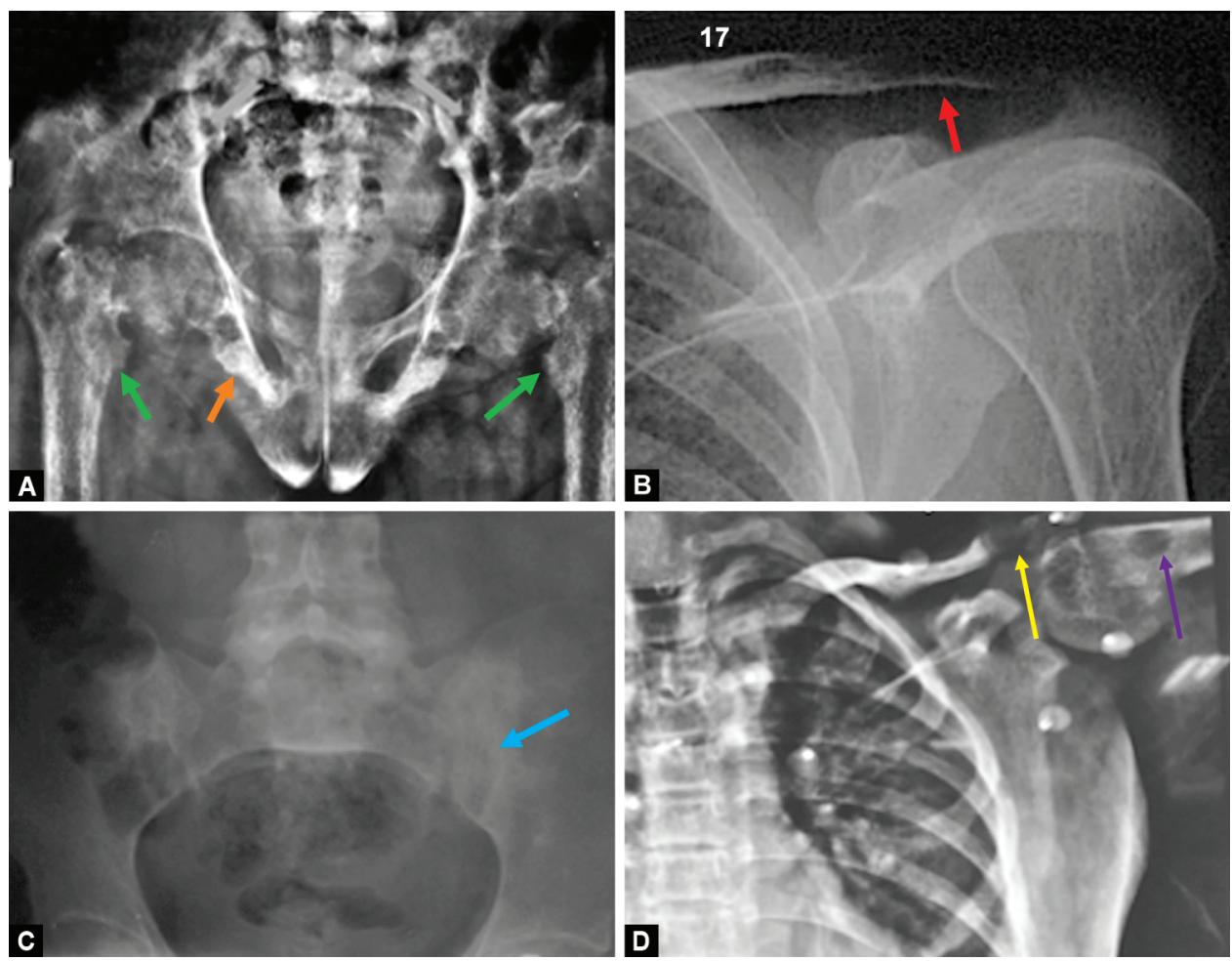

Figs 3 A to D: In a known case of PTHPT: (A) X-ray pelvis shows subligamentous resorption at bilateral trochanters (green arrows), ischial tuberosities (orange arrow) with subchondral resorption seen at bilateral sacroiliac joints, predominantly along with the iliac blades (blue arrow in C); (B) Subligamentous resorption along with the inferior surface of clavicle (red arrow); (C) Shows subchondral resorption at sacroiliac joint. (D) Chest X-ray shows subchondral resorption with a widening of acromioclavicular joint space and irregular fraying of articular margins of the clavicle (yellow arrow). A lytic lesion is seen in the neck of the humerus (purple arrow) represents brown tumor
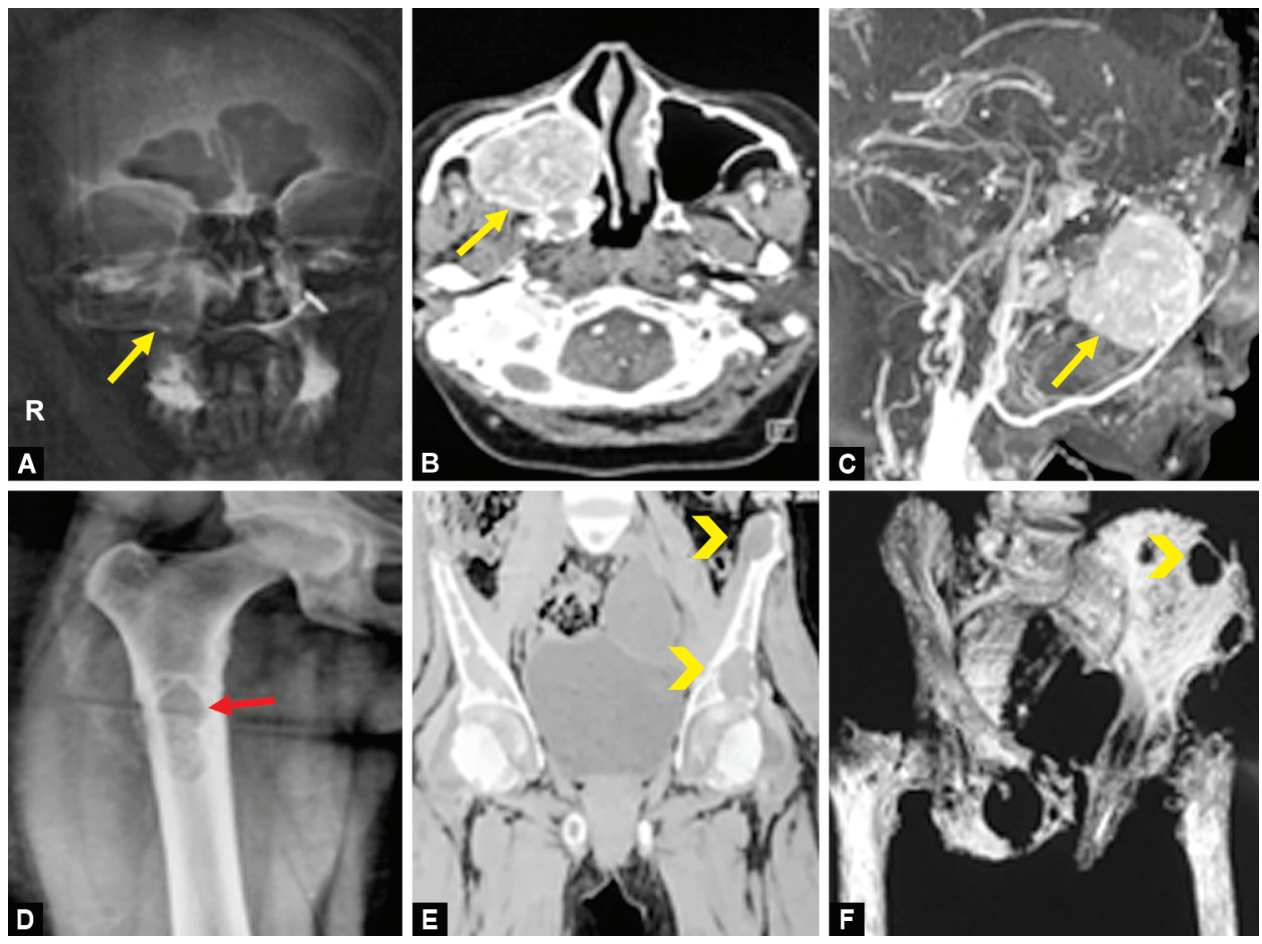

Figs 4A to F: Brown tumor. In a known case of PHPT: (A) Skull AP views show a radiopacity involving right maxillary sinus (notched arrow); (B) Shows brilliantly enhancing tumor on post-contrast CT scan; (C) Maximum intensity projection image of the same tumor shows a highly vascular lesion with supply from the external carotid artery. All features favor a brown tumor. In another patient of PHPT: (D) A lytic expansile, cortical-based lesion with a narrow zone of transition and sclerotic margins in the right femur proximal diaphysis (red arrow). (E) and (F) are CT and volume-rendered tomography images showing multiple lytic lesions in the acetabulum and left iliac blade with associated soft tissue components (arrowheads) 

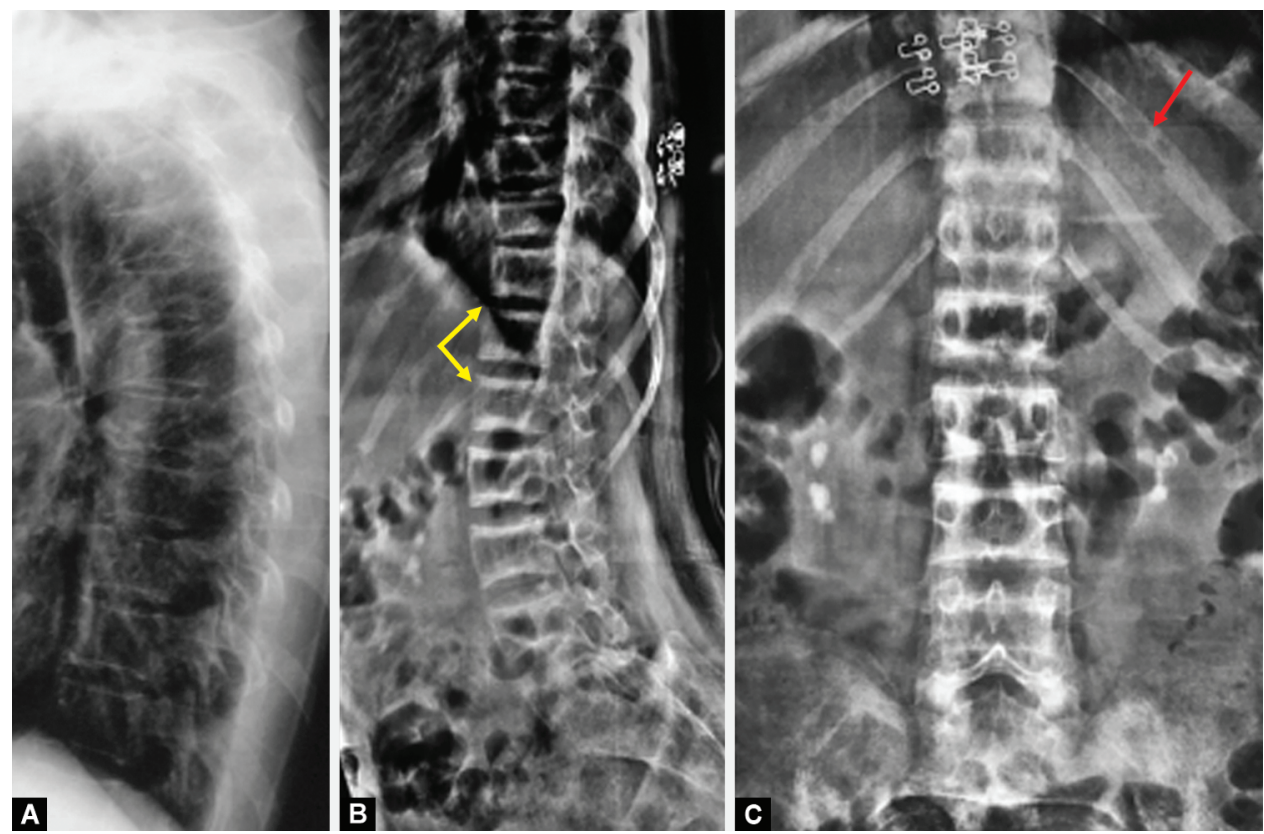

Figs 5A to C: In a known case of PTHPT: (A) Shows lateral X-ray of the spine with diffuse osteopenia and cortical thinning. (B) and (C) are lateral $\mathrm{X}$-ray of the spine showing rugger jersey spine with areas of sclerosis at the endplates of vertebrae (yellow arrows) with generalized osteopenia of the bones. (C) X-ray abdomen showing rugger jersey spine with lytic lesions/brown's tumor in left lateral ribs (red arrow)

done in patients with brown tumors involving the vertebral column specifically to look for extension into the spinal canal or any cord compression. ${ }^{8}$ These tumors show intense uptake on nuclear bone scans. ${ }^{4}$ The other differentials for these lytic bone lesions in the absence of other PHPT features include giant cell tumors, multiple myeloma, fibrous dysplasia, and metastases. These lesions show near-total regression after parathyroidectomy and surgery excision of the tumor may be rarely indicated for lesions not showing any regression post parathyroidectomy or causing a compressive effect on adjacent structures, associated with pathological fractures or for lesions recurring post parathyroidectomy. ${ }^{10}$

\section{Diffuse Osteopenia}

In the PHPT, there is resorption of non-weight bearing trabeculae of the bones and accentuation of the weight-bearing trabeculae, thus causing generalized asymmetric osteopenia of the entire skeleton. These features manifest on a radiograph in the form of prominent vertical striations, thinning of the cortex, and prominent corticomedullary differentiation of the bone especially seen in the vertebrae (Fig. 5A). Differentials for diffuse osteopenia include geriatric and postmenopausal osteoporosis which show preferential involvement of axial skeleton compared to PHPT induced osteopenia which predominantly affects the peripheral skeleton. ${ }^{1}$

In cases of secondary hyperparathyroidism, the osteosclerotic effect on the axial skeleton shows a classic "rugger-jersey spine" pattern where alternate areas of increased (along vertebral endplates) and decreased density (vertebral body) is observed (Figs 5B and C).

One of the major limitations of the skeletal survey is radiation exposure. Although no standard guidelines are available on the radiation dose exposure during the skeletal survey, and an average study involves nearly 10-15 X-rays. ${ }^{11}$ However, given the risks and benefits of imaging in a suspected case of PHTP, an astute clinician must decide what best suits every individual case.
Several modalities are available for the detection of bone density apart from radiographs, which include-dual-energy X-ray absorptiometry (DEXA) and quantitative ultrasonography, highresolution $\mathrm{CT}$, and a trabecular bone score (TBS).

\section{DEXA}

Bone mineral density can be calculated by means of DEXA, wherein the values are usually obtained calculated for the lumbar vertebrae, femur, and distal $1 / 3$ of the radius (preferred site of measurement in PHPT due to presence of dominant cortical bone). ${ }^{1}$ Thus, DEXA scan shows the reduction of bone mineral density at distal $1 / 3$ of the forearm (which is composed primarily of cortical bone), while the bone density of lumbar spine (which is formed mainly of trabecular bone) is preserved.

Trabecular bone score value can be derived from the DEXA scan. It can predict the risk of osteoporotic fractures and therefore can contribute to decision-making for definitive parathyroidectomy for patients suffering from PHPT. ${ }^{12,13}$ Studies have shown that the bone density at hips and lumbar region improved in patients postparathyroidectomy. ${ }^{14}$

\section{Conclusion}

The imaging features of PHPT on a skeletal survey are very classical in the form of subperiosteal resorption in hands, salt pepper appearance of a skull, acroosteolysis, diffuse osteopenia of peripheral skeleton, and browns tumors. A systematic approach to the skeletal survey will prevent misdiagnosis and will help the clinicians in better patient management by improving the quality of life for these patients.

\section{References}

1. Khedr A. Skeletal Manifestations of Hyperparathyroidism. Anatomy, Posture, Prevalence, Pain, Treat Intervent Musculoskele Disord 2018;6:88-96. 
2. Khan A, Bilezikian J. Primary hyperparathyroidism: pathophysiology and impact on bone. CMAJ 2000;163(2):184-187.

3. Murphey MD, Sartoris DJ, Quale JL, et al. Musculoskeletal manifestations of chronic renal insufficiency. Radiographics 1993;13(2):357-379. DOI: 10.1148/radiographics.13.2.8 460225.

4. Bennett J, Suliburk JW, Morón FE. Osseous manifestations of primary hyperparathyroidism: Imaging findings. Int J Endocrinol 2020;21:3146535. DOI: 10.1155/2020/3146535.

5. Resnick D, Deftos LJ, Parthemore JG. Renal osteodystrophy: magnification radiography of target sites of absorption. AJR Am J Roentgenol 1981;136(4):711-714. DOI: 10.2214/ajr.136.4.711.

6. Chang CY, Rosenthal DI, Mitchell DM, et al. Imaging findings of metabolic bone disease. Radiographics 2016;36(6):1871-1887. DOI: 10.1148/rg.2016160004.

7. Khalatbari MR, Moharamzad Y. Brown tumor of the spine in patients with primary hyperparathyroidism. Spine 2014;18(39):1073-1079. DOI: 10.1097/BRS.0000000000000455.

8. Hong WS, Sung MS, Chun KA, et al. Emphasis on the MR imaging findings of brown tumor: a report of five cases. Skeletal Radiol 2011;2(40):205-213. DOI: 10.1007/s00256-010-0979-0.
9. Jouan A, Zabraniecki L, Vincent $V$, et al. An unusual presentation of primary hyperparathyroidism: severe hypercalcemia and multiple brown tumors. Joint Bone 2008;2(75):209-211. DOI: 10.1016/j. jbspin.2007.03.004.

10. Glushko T, Banjar SSA, Nahal A, et al. Brown tumor of the pelvis. Cleve Clin J Med 2015;12(82):799-800. DOI: 10.3949/ccjm.82a.14146.

11. Berger RP, Panigrahy A, Gottschalk $S$, et al. Effective radiation dose in a skeletal survey performed for suspected child abuse. J Pediatr 2016;4(171):310-312. DOI: 10.1016/j.jpeds.2016.01.017.

12. Silva $B C$, Broy $S B$, Boutroy $S$, et al. Fracture risk prediction by non-BMD DXA measures: the 2015 ISCD official positions. Part 2: trabecular bone score. J Clin Densitom 2015;3(18):309-330. DOI: 10.1016/j. jocd.2015.06.008.

13. Boutroy S, Bouxsein ML, Munoz F, et al. In vivo assessment of trabecular bone microarchitecture by high-resolution peripheral quantitative computed tomography. J Clin Endocrinol Metabol 2005;12(90):6508-6515.

14. Cipriani C, Abraham A, Silva BC, et al. Skeletal changes after restoration of the euparathyroid state in patients with hypoparathyroidism and primary hyperparathyroidism. Endocrine 2017;2(55):591-598. DOI: 10.1007/s12020-016-1101-8. 